\title{
IMPACTO DE LA GLOBALIZACIÓN EN LOS MAYAS YUCATECOS
}

\author{
Luis Alfonso Ramírez Carrillo \\ Centro de Investigaciones Regionales Dr. Hideyo Noguchi \\ Universidad Autónoma de Yucatán
}

Los estudios mayas en Yucatán tienen una indudable tradición; no se remontan, como se podría pensar, a unas cuantas décadas, sino que venimos reflexionando sobre los mayas de manera sistemática y científica cuando menos desde finales del siglo xix. El arqueólogo Víctor Segovia comentaba que los yucatecos le deben tanto a los mayas que, de no ser por ellos, la mayor parte del mundo no sabría que en un mapa se encuentra la península de Yucatán. Las investigaciones sobre los mayas son muestra también de esta deuda. Aunque el interés por ellos puede trazarse prácticamente desde los descubridores y los cronistas, como Landa y López Cogolludo, en los siglos xvı y posteriores, los primeros estudios sistemáticos sobre la agricultura yucateca y el campesinado pueden ubicarse a mediados del siglo xix. ${ }^{1}$ Ya en Los indios de Yucatán ${ }^{2}$ de Justo Sierra O’Reilly, publicado como una reflexión que buscaba las raíces profundas de la guerra de castas, aparecen constantes consideraciones sobre sus prácticas agrícolas, pero más aún, toda la obra planteaba, hace siglo y medio, las mismas preguntas que nos seguimos formulando ahora. ${ }^{3}$ ¿Cómo impacta el cambio so-

\footnotetext{
' Ya en el Registro Yucateco, una de las primeras revistas editadas por Justo Sierra O'Reilly en Campeche entre 1845 y 1849, se constata el gran interés, no sólo por las costumbres históricas de los mayas del siglo xix, sino por las transformaciones ocurridas en las primeras décadas independientes del siglo xix. Así lo demuestra J. Sierra cuando se esfuerza en reproducir el "Informe dado por el cura de Yaxcaba, D. Bartolomé del Granado Baeza, en contestación al interrogatorio de 36 preguntas, circulado por el Ministerio de Ultramar, sobre el manejo, vida y costumbres de los indios, que acompañó el Ilmo. St. Obispo a la diputación provincial", elaborado el 1 de abril de 1813 ("Los indios de Yucatán", Registro Yucateco, 1845, pp. 165-178).

${ }^{2}$ La inquietud sobre la transformación social de los mayas ya estaba presente en Justo Sierra, que en aquél entonces redactaba sus "Indios de Yucatán", publicado años después. Del informe del cura Granado dice: "Todo en el es exactísimo, y lo que a primera vista no aparece enteramente conforme a la verdad, tenga presente que consiste en que del año 13 al actual, han tenido muy notable alteración las costumbres de los indígenas... merced al influjo de la ilustración... que se ha extendido... desde que la libertad de imprenta ejerce en Yucatán su dominio" (Registro Yucateco, 1851: 178). Véase también de J. Sierra O'Reilly, Los indios de Yucatán. Consideraciones históricas sobre la influencia del elemento indigena en la organización social del pais.

${ }^{3}$ Sierra y una brillante generación de intelectuales liberales, la de 1840 , iniciaron una prolongada y seria labor de reflexión histórica a través de la prensa. Sierra fundó la publicación periódica, El Museo Yucateco, que se editó entre 1841 y 1842, y en ella escribió más de 70 artículos. la mayor parte de tema histórico-literario, y es raro encontrar alguno en el que no se haga refe-
} 
cial en una cultura tradicional? ¿Cómo se socavan las formas de organización social? ¿Cuál es la respuesta de una tradición milenaria a la modernidad? No olvidemos que durante el xIx, gracias a la imprenta, la independencia y el liberalismo, se dieron transformaciones más profundas en la sociedad indígena maya que en los tres siglos anteriores, y que además el liberalismo de la segunda mitad del siglo se parece extraordinariamente a lo sucedido en México a partir de 1982, cuando la sociedad y el Estado se reestructuran con un modelo neoliberal.

El interés por los mayas ha continuado. No sólo historiadores y arqueólogos, como Silvanus Morley ${ }^{4}$ y Eric Thompson, ${ }^{5}$ han estudiado los sistemas sociales del pasado, también académicos locales que, sin ser investigadores profesionales, nos ofrecen una visión de la sociedad campesina y sus transformaciones, lo cual los convierte en verdaderos pioneros en los estudios mayas y campesinos. Desde los años veinte del siglo pasado encontramos gente como Augusto Pérez Toro ${ }^{6}$ con estudios sobre la milpa, las prácticas rituales y los cambios sociales de los mayas; Narciso Souza, ${ }^{7}$ que se abocó a las prácticas botánicas; Alfredo Barrera Vázquez, ${ }^{8}$ que no sólo hizo análisis filológicos sino también reflexiones sobre el cambio social en la organización de los mayas del siglo xx; Narcisa Trujillo, ${ }^{9}$ que se centró en los mayas de las haciendas henequeneras; el profesor Santiago Pacheco Cruz, ${ }^{10}$ con sus detalladas descripciones etnográficas de los mayas de Quintana Roo, por no hablar de los resultados acerca de la organiza-

rencia a la sociedad indígena maya, aunque predomine la visión liberal de los historiadores del siglo xix.

${ }^{4}$ Morley no sólo se interesó por los mayas arqueológicos sino también por los mayas contemporáneos que observó en Yucatán en los años veinte y treinta del siglo xx, como puede apreciarse tanto en su correspondencia como en las primeras páginas de su libro La civilización maya (1965: 28-52).

${ }^{5}$ Un interés etnográfico similar lo encontramos en Thompson de manera temprana (1930) y en las paginas introductorias de The rise and fall of maya civilization (1954). No olvidemos que tanto Thompson como Morley se vieron influidos por los trabajos de J. L. Stephens, quien, a pesar de tener como interés central la arqueología, hizo notables descripciones de los mayas del xix (1841 y 1843).

${ }^{6}$ Pérez Toro, agrónomo experto, formado en la Universidad de Columbia, se interesó muy temprano por la agricultura indígena de México desde una perspectiva etnológica. Muy joven participó en el proyecto Carapan que dirigía Moisés Sáenz entre los tarascos de Michoacán (véase su ensayo sobre Yucatán de 1977). Cfr. L. A. Ramírez, Chilchota, un pueblo al pie de la sierra (1986), respecto a la presencia de Pérez Toro en el proyecto Carapan.

${ }^{7}$ De los estudios etnobotánicos de Narciso Souza (1948) se infieren numerosas prácticas de medicina tradicional maya.

${ }^{8}$ De la extensa bibliografía de Barrera Vázquez véanse, como meros ejemplos, 1977 y 1980.

${ }^{9}$ Trujillo (1977).

${ }^{10}$ La obra del profesor rural Santiago Pacheco Cruz ha sido poco apreciada. Si bien sus interpretaciones son polémicas, al igual que su estilo literario —en el que de manera personal decidió eliminar la $y$ griega de la gramática española-, sus descripciones etnográficas son muy ricas y deben ser revaloradas. Véanse, por ejemplo, su Antropología cultural maya (1962, tomo I) y (1964, tomo II). 
ción social rural de la época, que arrojó el proyecto de Chichén, impulsado por la institución Carnegie y la Universidad de Harvard. ${ }^{11}$ Además contamos con la investigación sobre los mayas de Yucatán de Morris Steggerda, ${ }^{12}$ que realizó el primer estudio sistemático sobre cultura y personalidad, y en ese sentido, sobre la identidad de los campesinos mayas con un enfoque psicoanalítico, incluso aplicando numerosos tests de Roscharch. Existen también, por supuesto, los textos más conocidos con los que se piensa que comienza la investigación moderna sobre los mayas yucatecos: son los trabajos clásicos de Robert Redfield, ${ }^{13}$ Azael Hansen ${ }^{14}$ y Alfonso Villa Rojas, ${ }^{15}$ que de manera central tocan ya temas como la modernización y, un poco más de fondo, la dinámica del cambio social entre los mayas de Yucatán. Así pues, el continuo folk-urbano se convirtió en un primer paradigma de referencia, el cual, debido a su carácter funcionalista, fue criticado por algunos antropólogos, quienes piensan que hacen algún descubrimiento con su crítica, medio siglo después de publicadas y superadas sus obras, además de que escriben tesis y ponencias en su contra con ingenuidad. ${ }^{16}$ Los estudios mayistas sufren una interrupción entre 1950 y 1970 , y vuelven a

${ }^{11}$ El museo Peabody de Arqueología y Etnología de la Universidad de Harvard, entre 1888 y 1915, envió numerosas expediciones al territorio maya. Este esfuerzo fue continuado de 1924 a 1940 por la Carnegie Institution de Washington a través del proyecto Chichén, liderado por Silvanus Morley, y aunque fue arqueológico en esencia generó inquietudes etnográficas.

${ }^{12}$ Steggerda fue un antropólogo físico, pionero en los estudios de cultura y personalidad en el área maya. Había hecho investigaciones de antropología física en el área del Caribe y emprendió una larga etnología de los mayas contemporáneos alrededor de Chichén Itzá, en especial en el poblado de Pisté. Véase en particular su Maya Indians of Yucatán (1941).

${ }^{13}$ Redfield es el punto de partida obligado de la antropología cultural contemporánea de los mayas yucatecos. Representante clásico de la escuela de Chicago, su enfoque culturalista, de gran sencillez y limitación teórica, representó sin embargo uno de los primeros modelos integrales para entender la lógica de cambio social de los mayas yucatecos. Cfr. Redfield (1941) y, en colaboración con Villa Rojas (1934).

${ }^{14}$ Hansen formó parte del equipo de Redfield, y era el que supuestamente se ocuparía de la cuarta comunidad del continuo folk-urbano: Mérida. Sin embargo, aunque realizó el trabajo de campo en los años treinta, no escribiría el libro sobre Mérida sino hasta que otro académico trabajó con él sus notas en 1980. Cfr. Hansen y Bastarrachea (1984).

${ }^{15}$ Villa Rojas es uno de los grandes etnólogos de los mayas yucatecos. Reclutado por Redfield y formado también en la escuela de Chicago, se enfocó en especial en las características culturales de los mayas de Quintana Roo; véase The Mayas of East Central of Quintana Roo, traducido como Los elegidos de Dios, en 1978.

${ }^{16} \mathrm{Si}$ bien el modelo del continuo folk-urbano es insostenible y ha sido criticado por su falta de capacidad para dar cuenta de la dinámica social, del conflicto, de la estratificación, y por su falta de historicidad, etc., esta crítica se desarrolló sobre todo en los años cincuenta y principios de los sesenta. Como construcción intelectual, este modelo, pese a su aparente sencillez, continúa siendo uno de los paradigmas teóricos mejor estructurados, en cuanto a su lógica interna, sobre la sociedad maya. Es un punto de referencia obligado en la historia de la construcción conceptual de los mayas yucatecos. Sin embargo, muchos principiantes y estudiosos superficiales de los mayas insisten en comenzar sus trabajos criticando a Redfield, demoliendo lo demolido y haciendo gala de ignorancia antropológica; mostrando en consecuencia su incapacidad para construir nuevos modelos interpretativos de interés. 
ser cultivados en los años setenta con diversos puntos de vista, ya sea desde un marxismo tradicional, un enfoque chayanovista, o la polémica campesinistasdescampesinistas. Se reanuda la discusión sobre el campesinado y los mayas de Yucatán impulsada en gran medida por la profunda crisis de los campesinos henequeneros y la dramática pobreza del estado. Armando Bartra, ${ }^{17}$ Arturo War$\operatorname{man}^{18}$ y Luisa Paré ${ }^{19}$ no dejaron de hablar de los campesinos mayas yucatecos, al igual que numerosos investigadores locales, algunos de los cuales se asomaron someramente al tema y continuaron su camino, y otros han permanecido en él. Me refiero a gente como Eric Villanueva, ${ }^{20}$ Mauricio Macossay ${ }^{21}$ u Othón Baños, ${ }^{22}$ entre otros.

\section{Impacto de la globalización entre los mayas de la península de Yucatán. Principales tendencias.}

En la actualidad podríamos hablar del impacto de la globalización con frases lapidarias y alarmistas como las de brutal aculturación, pauperización extrema o empobrecimiento de la identidad cultural de los mayas peninsulares yucate$\cos -\mathrm{o}$ cualquier nueva carga de significados que le otorguemos a este concepto- La pauperización económica y la transformación de las identidades son hechos innegables entre los mayas contemporáneos. Atribuirlo de manera especial a la apertura comercial de México y a los procesos de globalización económica y mundialización de la cultura de las últimas dos décadas, ensombrece el hecho histórico de un proceso de sojuzgamiento cultural y empobrecimiento progresivo que es ya centenario, en donde la desigualdad social y el escamoteo histórico de oportunidades de desarrollo social y étnico nos expli-

\footnotetext{
${ }^{17}$ Bartra, en una breve estancia en el Centro de Investigaciones Regionales Dr. Hideyo Noguchi de la Universidad Autónoma de Yucatán, reflexionó desde la óptica de los estudios campesinos (1978).

${ }^{18}$ Warman condujo un equipo de antropólogos y estudiantes de la UAM, estudiando en especial la agricultura de los mayas yucatecos durante varios meses de campo en Yucatán. Aparte de algunas tesis, este proyecto fructificó en un breve ensayo (1985).

${ }^{19}$ Luisa Paré trabajó sobre todo problemas de ecología humana entre los mayas del litoral yucateco (1982).

${ }^{20}$ Véase Villanueva (1983) y el conjunto de ensayos que agrupó como coordinador en 1990.

${ }^{21}$ Macossay (1988 y 2004).

${ }^{22}$ Baños es el autor que con más cuidado ha dado cuenta de la transformación del campesinado maya henequenero, caracterizando todo el proceso de desarticulación de la sociedad rural basada en la plantación henequenera, véanse Baños (1996 y 2003). En el debate sobre los mayas como campesinos henequeneros fueron importantes las reflexiones iniciadas por un grupo de académicos locales agrupados en los departamentos de Estudios Económicos y Sociales (DEES) y de Estudios Sobre Cultura Regional de la Universidad Autónoma de Yucatán, a partir de 1978. Múltiples ejemplos pueden encontrarse en los números de la revista Yucatán: Historia y Economía, de 1977 a 1983, DEES-UADY, luego llamada Región y Sociedad, 1986-1987, DEES-UADY, y en la Revista de la Universidad Autónoma de Yucatán, de los años ochenta.
} 
can con mayor claridad la situación contemporánea que los procesos de corto plazo. Pero antes, aclaremos algunos conceptos: ¿qué entendemos por globalización en México, y en particular en la península de Yucatán?

El uso de este término se ha extendido tanto para bautizar tantas cosas distintas que, al igual que otros conceptos "paraguas", como identidad o cultura, corre el riesgo de quedar vacío. ${ }^{23}$ No intento discutir su centenar de definiciones $;^{24}$ de manera sencilla, en el contexto de estas líneas, globalización tiene dos órdenes de significados. Uno de carácter económico, que se refiere al movimiento centrífugo de empresas y capitales de los sectores del comercio, de la industria y los servicios de las naciones ricas y más industrializadas y a las más pobres y menos industrializadas, o bien de las naciones en desarrollo que buscan ventajas comparativas para movilizar su base industrial. En México este proceso tiene 20 años. Los primeros 10, de baja intensidad, con la apertura iniciada en 1984 y refrendada en 1987 con el ingreso del país al GATT, y los últimos 10 de alta intensidad e impacto, a partir de la firma del Tratado de Libre Comercio en 1993.

Un segundo orden de significados se aleja del carácter económico y tiene que ver con el proceso de mundialización de la cultura impulsado por dos hechos: la penetración de los mensajes ideológicos y culturales de los medios masivos de comunicación y la transformación de los hábitos y productos de consumo, que implican nuevas formas de apropiarse del mundo y sus sentidos en lo individual, en lo familiar y en lo cotidiano, proceso del que ninguna clase social ni grupo étnico ha estado exento la última década en México, y en el que los mayas peninsulares vienen participando con singular intensidad.

Pero, ¿quiénes son los mayas peninsulares? Con 800000 hablantes de la lengua maya, Yucatán sigue siendo el cuarto estado con mexicanos a los que nosotros queremos llamar o que se llaman a sí mismos indígenas, en números totales. Le anteceden en este honor Oaxaca, Veracruz y Chiapas. Pero después de Oaxaca, es la segunda entidad con mayoría indígena respecto a su total de pobladores, ya que si en Oaxaca, indígenas y no indígenas están uno a uno, en Chiapas sólo $30 \%$, y en Veracruz menos de $19 \%$ pueden ser considerados indíge-

\footnotetext{
${ }^{23}$ En realidad el término globalización, del que afirmamos que impacta a los mayas yucatecos, es un concepto que engloba numerosos procesos muy distintos entre sí, desde la presencia de las compañías transnacionales hasta la penetración de los medios de comunicación, pasando por un intento de un nuevo trato por parte del Estado mexicano a los pueblos indígenas. Su origen es netamente económico, provino de las escuelas de negocios del este de Estados Unidos y de la reflexión sobre la industrialización global, como puede verse en estudios pioneros donde se utiliza el tema como el de M. Porter (1986) y Ohmae (1986).

${ }^{24}$ La bibliografía sobre el impacto de la globalización sobre lo local y la identidad es cada vez más amplia. Véanse los ensayos "The local-global nexus" y "Modernity and identity: a Symposium", en International Social Science Journal, 1988; Borja y Castells (2002); Lerman (1999); Ianni (1999); Barman (1999). Son en especial interesantes el conjunto de ensayos agrupados en América latina 2020, López y Filmus (2000). Para Yucatán véase Ramírez Carrillo (2003: 191-219), Azaiz (2003: 377-419) y Gravel (2003: 355-376), todos en J. Preciado et al., coords., Territorios, actores y poder ( 2003).
} 
nas desde el año $2000 .^{25} \mathrm{Si}$ se incorporan otros indicadores como población rural menor de cinco años y apellidos mayas, el índice vuelve a ubicarse en la mitad del contingente demográfico, y Yucatán, junto con Oaxaca, vuelve a quedar como uno de los estados de la República con mayor población indígena. Pero a diferencia de Oaxaca, esta mayoría corresponde a un único grupo étnico: los mayas. Es también el estado con la población maya más numerosa de los tres que comprenden la península de Yucatán, pues Campeche se ubica en $20 \%$ y Quintana Roo, debido a su fuerte inmigración, en $25 \%$ del total de sus pobladores. ${ }^{26}$

\section{Regiones mayas}

La homogeneidad nos presenta una serie de rasgos culturales compartidos que se manifiestan en la lengua y que nos hablan por un lado de un universo simbólico y una visión del mundo, y por el otro de formas de organización social comunes a toda esta población, sin dejar de hacer notar las variantes culturales que la historia y la geografía han impuesto. Entre las más notables, en el caso de Yucatán, están las diferencias entre los mayas de la zona henequenera, los de las zonas maiceras del sur y del oriente, y de todos ellos con los mayas que han migrado desde 1950 hacia los centros urbanos del estado, fundamentalmente la ciudad de Mérida.

Hay que destacar en especial algunas comunidades donde la tradición maya se ha mantenido con una fuerza particular. Se trata de las comunidades de Chemax, Kanxoc y Xocén, así como algunos pueblos y rancherías cercanas a ellas, ubicadas en la frontera con Quintana Roo, en el oriente del estado. En estas comunidades la cultura maya alcanza expresiones de carácter político y de culto religioso que no se encuentran ya de manera tan estructurada en otras partes de Yucatán, como serían el sistema de cargos, las guardias militares, el significado del padrinazgo, la personalidad religiosa de los líderes y el culto a la cruz. ${ }^{27}$

\footnotetext{
${ }^{25}$ Según los cálculos de la Comisión para el Desarrollo de los Pueblos Indígenas, que supera los de los últimos censos de población del INEGI del año 2000, al incluir a la población menor de cinco años y a la que tiene apellidos indigenas. Si consideramos los datos del INEGI, Yucatán seguía siendo el estado con mayor población hablante de lengua indígena de México, con 37.3\% del total (INEGI, 2000).

${ }^{26} \mathrm{En}$ el 2000 la población total de lengua indígena en los tres estados de la península de Yucatán era de 816889 (25.3\% de la población mayor de 5 años). En Yucatán había 549532 (37.3\% de su población total); en Campeche 93765 (15.4\% de su población total), y en Quintana Roo 173592 (22.9\% de su población total). En 1990 era de 525264 (43.8\%); 86676 (15.4\%), y 133081 (29.2\%) respectivamente. De estos hablantes de lenguas indigenas la población maya hablante en el 2000 era de 99.5\% en Yucatán, $80.9 \%$ en Campeche y $94.1 \%$ en Quintana Roo (Güémez Pineda, 2004). En resumen, la homogeneidad maya en la península es clara, al igual que un crecimiento en el número absoluto de hablantes de maya (en 1970 en la península había 454675 contra más de 800000 del 2000) y un decrecimiento en el número relativo.

${ }^{27}$ Los remanentes del culto a la cruz y el sistema de guardias entre los mayas de Quintana Roo han sido ya estudiados, aunque su interpretación aún guarda gran potencial teórico. Este rasgo
} 
Estas diferencias de carácter regional han sido producto de los distintos ritmos con los que se han desarrollado las actividades productivas vinculadas al mercado en cada región del estado y de las vocaciones económicas que desde el siglo xix se han venido desarrollando en cada uno de ellos. La modificación de los sistemas de organización del trabajo, de las condiciones del acceso a la tierra, la expansión de la red de caminos y la alfabetización y castellanización - uno de los pocos logros del sistema educativo formal implantado desde los años treinta por las misiones culturales cardenistas - , han trabajado para integrar la cultura maya a la cultura nacional. Después de más de 50 años, este conjunto de factores nos permite identificar diferencias culturales dentro del estado de Yucatán, que nos muestran regiones con distintos grados de cambio y persistencia de tradiciones, hábitos y formas de organización social de la cultura maya histórica.

Entre los cambios más visibles se encuentran, como es de esperarse, la distinta "pureza", "adulteración" o habilidad en el manejo del idioma maya, ${ }^{28}$ el uso o desuso de la ropa maya considerada como tradicional, que se desarrolló durante la colonia y el siglo xix (huipiles bordados, rebozos y pies descalzos en las mujeres; ropa de manta blanca y huaraches en los hombres), las prácticas religiosas y el culto a seres sobrenaturales asociados a los ciclos agrícolas, y en especial al cultivo del maíz, el conocimiento del ciclo lunar y su influencia en la milpa, las prácticas vinculadas a los momentos importantes del ciclo de vida, como el nacimiento, el padrinazgo y su conjunto de acciones rituales, como el hetz mec, la pubertad, el matrimonio, la enfermedad y la muerte, el culto a los muertos, y el uso de los subsistemas agrícolas asociados al solar. ${ }^{29}$

Cabe hacer notar que en general hay una marcada desaparición de las formas tradicionales de gobierno indígena y de manifestaciones de organización social que nos hablen de una expresión política organizada de la comunidad maya frente al poder de Estado y de sus formas de gobierno, como sería el sistema de cargos bien estructurado o la elección de autoridades a través de los distintos sistemas de usos y costumbres que existen en otros grupos indígenas mexicanos..$^{30}$ Las únicas manifestaciones de una vida comunal organizada que se encuentran de manera uniforme en todos los pueblos mayas de Yucatán, de la zona henequenera y de la maicera, y en los pueblos más conservadores ya mencionados, son aquellas que han sido cobijadas por la Iglesia católica, como los gremios y las fiestas del santo patrono de cada pueblo. ${ }^{31}$

tan particular de los mayas se encuentra en grave deterioro por la globalización, a través del turismo de Cancún y las migraciones temporales. Para su descripción original véase Villa Rojas, op. cit. y Bartolomé y Barabas (1977). Para documentar su transformación véase Sullivan (1991) y Dufresne (1999).

\footnotetext{
${ }^{28}$ Véase Pfeiler (1997).

${ }^{29}$ Fay Brown (1993).

${ }^{30}$ Mossbrucker (1992).

${ }^{31}$ Véase Re Cruz (1994 y 1996).
} 
El proceso generalizado de desaparición de las expresiones políticas formales de la cultura maya tradicional se aceleró después de la llamada Guerra de Castas, pues se veía como un peligro la existencia de cualquier tipo de expresión del poder indígena. Esto fue en especial rápido en el norte de Yucatán y en torno a la ciudad de Mérida, debido a la expansión de la hacienda henequenera, que durante medio siglo disminuyó la importancia de los pueblos indígenas como centros de población. Sin embargo, hemos mencionado ya las comunidades donde es posible encontrar un poder local que se expresa bajo formas de gobierno propias legítimas por un poder religioso y asociadas con el culto a la cruz. ${ }^{32}$

En las zonas maiceras del sur y oriente, en donde la milpa sigue siendo el principal sustento de los campesinos mayas, encontramos también el reconocimiento a autoridades tradicionales que intervienen en el espacio productivo para regular el acceso a la tierra y para ayudar a solucionar conflictos, más que de propiedad, de derechos de usufructo de las distintas partes del monte por los grupos familiares que habitan los pueblos. Otros personajes que acumulan poder y que se desenvuelven tanto en el ámbito público como en el de la vida privada y simbólica, son aquellos que desempeñan algún tipo de actividad religiosa que los vincula con los dioses o con el panteón maya, los denominados h-menob. Junto a ellos están los considerados hierbateros, o sea, los que tienen un conocimiento efectivo de la flora y la farmacopea tradicional, o bien los que sin caer en ninguna de estas dos categorías, son considerados como brujos o gente con capacidad de hacer el bien y el mal mediante acciones rituales. ${ }^{33}$

Aunque en ocasiones esos personajes distinguidos de la comunidad y los líderes naturales pueden ser los mismos, por lo general los ámbitos de interacción tienden a diferenciarse en la vida de cada pueblo. Esto significa que si bien la tendencia a la aparición de hombres fuertes o caciques que asumen el liderazgo en las comunidades mayas puede relacionarse con su legitimación previa como portadores y practicantes de aspectos importantes de la cultura tradicional, no siempre es así, y hay un amplio margen para el juego de facciones y la imposición de personalidades fuertes que no responden a un sistema político tradicional estructurado.

Esta situación es más clara en la zona henequenera donde las formas de gobierno tradicional se perdieron desde fines del siglo xix, ante el avance de las haciendas sobre comunidades que, además, se habían visto ya impactadas demográfica y políticamente por los movimientos de población que ocasionaron los primeros 10 años de la llamada Guerra de Castas. Las comunidades del sur y del oriente, aunque también afectadas por la guerra, tuvieron tiempo y un período de relativo aislamiento que les permitió mantener formas de vida y de or-

\footnotetext{
${ }^{32}$ Véase Sullivan, op. cit.

${ }^{33}$ La persistencia de hmèeno'ob (chamanes) hierbateros, culebreros, hueseros y médicos tradicionales es paradigmática y una de las más fuertes de los grupos indígenas de México (Ramírez, 2002 y Guiémez Pineda, s/f).
} 
ganización ancestrales. Las del sur, asentadas a lo largo del sinuoso eje de Ticul, Tekax, Oxkutzcab y Peto; las del oriente, en torno a Izamal y Valladolid.

El siglo xx profundizó la diferenciación regional de la población maya yucateca. Más de 400 comunidades indígenas del norte de la península, nucleadas por Mérida, fueron ocupadas durante más de un siglo por el monocultivo henequenero; hasta 1938, por la hacienda y después de esa fecha, por el ejido colectivo henequenero impulsado por Lázaro Cárdenas. ${ }^{34}$ La transformación de campesinos milperos a peones de hacienda, de peones a ejidatarios henequeneros y —desde los setenta hasta la fecha-, de ejidatarios a trabajadores agrícolas temporales o albañiles en Mérida y Cancún, modificó no sólo las bases de subsistencia, sino el sentido mismo de comunidad de esta población maya.

Junto con la temprana y densa red de comunicaciones requerida por la plantación, la presencia de escuelas y un sistema de salud oficial institucionalizado han modificado las manifestaciones y el contenido mismo de la cultura maya, vaciando de sentido muchas de sus prácticas, como los detallados rituales de la milpa, y volviendo insustanciales otras, como las fiestas de comunidad en la zona henequenera de Yucatán, que considerada en términos laxos, agrupa a 62 de los 98 municipios del estado considerados indígenas por el INI. ${ }^{35}$

Las comunidades mayas del sur y del oriente, en cambio, son más tradicionales, y han podido mantener rasgos culturales que van más allá del lenguaje y se manifiestan en los estilos de vida a nivel de la familia y la comunidad. Además de la lejanía de Mérida, esto es consecuencia de un mayor aislamiento en términos de red caminera, y en especial de una mayor dedicación a la milpa, que continúa siendo el eje sobre el que descansan los elementos más fuertes de la cultura cotidiana, el ritual y las creencias que otorgan sentido y hacen de la tradición una práctica. Las fronteras del maya milpero son las poblaciones que dependen de Peto hacia el sur, de Valladolid en el oriente y de Tizimín en el noreste.

En estas regiones, 37 municipios agrupan a una tercera parte de la población maya de Yucatán. Son mayas que aún dependen de la milpa, el frijol y la calabaza para sobrevivir, y no sólo como complemento alimenticio. Se trata de una población campesina que después de asegurar una mínima superficie de milpa, migra a buscar trabajo como peón agrícola, albañil o barrendero a otras partes de la península, pero que retorna a su pueblo combinando el salario con los ciclos de la naturaleza, manteniendo y modificando así el sentido actual de la cultura maya. ${ }^{36}$

Los mayas de la zona henequenera se dedican en su mayoría a actividades no agrícolas. ¿Qué es lo que esto significa? En primer lugar, significa una pobla-

\footnotetext{
${ }^{34}$ Para una descripción de los mayas henequeneros en los años treinta véase Askinasy (1936), en los cincuenta, Benítez (1962) y en los sesenta, Thompson (1974).

${ }^{35}$ Véase la regionalización de la población maya que plantea Ruz (2002), y en esa misma obra los ensayos de Bracamonte sobre Quintana Roo y Solís sobre Campeche, así como la tesis doctoral de Guzmán (2002).

${ }^{36}$ Véase Fay Brown (1999).
} 
ción que ha encontrado en la emigración temporal — como preámbulo en muchas ocasiones de la definitiva - una forma de vida. Muchos miles se ocupan en la industria de la construcción regional como albañiles. La construcción es una de las ramas que más empleo genera a nivel peninsular y que se ha recuperado con mayor rapidez de las crisis de 1982, 1987 y 1994. En 1996 la construcción ocupó a 5500 personas.

Muchos otros se emplean en actividades de limpieza y jardinería. Algunos más trabajan en la cosecha de la sal en las ciénegas de Yucatán y en la siembra y limpieza de los pastizales de la ganadería privada del sur y del oriente. Esto se combina con algún trabajo eventual en el henequén y con un poco de milpa mal hecha, por la falta de experiencia, la escasez de insumos y el poco tiempo que se le dedica, que da algo de maíz para comer y algunos frutales, hortalizas y animales criados en el solar.

Un elemento importante ha entrado en este conjunto de actividades. Se trata del trabajo de la mujer maya. Las estadísticas indican una participación creciente del trabajo femenino dentro de la Población Económicamente Activa y de la Población Ocupada de Yucatán. Si en 1970 era de 10\%, en 1990 alcanzó $20 \%$ a nivel estatal, y en 1995 se ubicaba a $38 \%$ a nivel urbano, y a $28 \%$ a nivel rural. ${ }^{37}$ En los municipios que nos ocupan, gran parte de estas mujeres trabajadoras son también migrantes. Viajan a la ciudad de Mérida o a los otros centros urbanos de la región para trabajar como sirvientas, lavanderas y nanas, trasladándose diariamente o regresando a sus pueblos los fines de semana, y se han convertido en muchos casos en el principal soporte económico de sus familias. En 1996, más de 8000 mujeres trabajaban como sirvientas en la ciudad de Mérida, aunque la cantidad no censada parece ser mayor. ${ }^{38}$

La nutrición, que es un indicador crítico de la pobreza extrema y de la marginación en todo el México rural, ha sido históricamente deficiente en la zona, al grado de que se plantea que ha existido una disminución masiva de talla y peso de la población maya. ${ }^{39}$ Esta situación no ha mejorado. El agudo desempleo en la zona henequenera y el impacto de las tres últimas crisis desde 1982 (la devaluación de 1982 provocada por la nacionalización de la banca, la primera quiebra de la bolsa de 1987 y la devaluación y quiebra de diciembre de 1994), mantienen a importantes porcentajes de la población maya en un estado de desnutrición crónica, y en los extremos más empobrecidos de ella podemos hablar con franqueza de hambre. Los indicadores de marginalidad, si bien altos para todos los municipios indígenas de Yucatán — que con excepción de siete se clasifican como de alta marginalidad - tienden a ser ligeramente superiores en los municipios indígenas de la zona henequenera. La tasa bruta

\footnotetext{
${ }^{37}$ Ramírez Carrillo (2002a).

${ }^{38}$ Id.

${ }^{39}$ Véanse los datos que manejan Askinasy (op. cit.) y Bonfil Batalla (1962); más recientemente Balam Pereira (1991y 2004).
} 
de mortalidad era en 1990 de $8 \%$ por cada mil habitantes, y en 1995 se ubicaba en $5.5 \%$. Las enfermedades más comunes son las de la pobreza, es decir, las gastrointestinales y las que afectan las vías respiratorias. La cuarta parte de la población no tiene agua entubada, y la mitad de la que está entubada no alcanza índices de potabilización adecuados. Entre 15 y $20 \%$ de las viviendas carece de energía eléctrica.

En toda esta región, las tierras comunales indígenas se volvieron ejidos entre 1920 y 1940 . Por decreto, la milpa tradicional comunitaria se limitó a 21 hectáreas de tierra por campesino en promedio. Tres hectáreas para el cultivo anual (dos de milpa-roza y una de milpa-caña) y 18 para recuperación. ${ }^{40}$ Esto redujo los períodos de barbecho del monte a menos de 12 años. Sin embargo, dada la disponibilidad de terrenos nacionales o de predios privados incultos, los indígenas mayas no se sujetaron a estos límites, sino que invadieron o rentaron a bajo precio los montes vecinos a sus comunidades, lo que les permitió mantener en mejor equilibrio el sistema de roza-tumba-quema y los cultivos asociados al maíz. Se antoja particularmente importante insistir en que no ha sido la densidad demográfica la que ha empezado a romper este equilibrio; lo ha hecho el avance constante de los pastizales necesarios para la ganadería extensiva, al grado de que ya en muchas comunidades mayas los ciclos de barbecho mínimo se han roto y se encuentra en peligro todo el ciclo de la milpa.

Lo anterior es de la mayor importancia si consideramos que la milpa es el soporte fundamental de la cultura maya. La milpa es una forma de vida y una articulación simbólica al mundo; es la base de un pensamiento cíclico en el que la vida y la muerte, el tiempo del pasar y del retorno se eslabonan. Es también lo que obliga a mantener una organización familiar definiendo papeles productivos y rituales de hombres y mujeres, de ancianos y de jóvenes. Si el maíz, el frijol y la calabaza de la milpa mantienen vivos a los mayas, los rituales asociados a cada una de las etapas de limpieza del monte, siembra, cultivo y cosecha, mantienen vivos a los dioses y a los personajes menores de la religión maya que aún sobreviven.

La milpa también obliga a generar un sentido de comunidad y normas de convivencia, para tener derechos de acceso al monte y regular su explotación por todos aquellos que se consideran miembros de un pueblo maya. La desaparición de la milpa significa a corto plazo la desaparición de la comunidad maya campesina, al menos como ésta ha sido concebida tradicionalmente.

El desequilibrio de este sistema productivo es un indicador directo del desequilibrio de la comunidad y de la cultura, al menos en su matriz tradicional. La dependencia entre la identidad maya y la milpa es directa. Si bien muchos agricultores pueden sembrar maíz, sólo un maya puede "hacer milpa" en Yucatán. ${ }^{41}$

\footnotetext{
${ }^{40}$ Véanse Fort (1979) y Ramírez Carrillo (2000).

${ }^{41}$ Véase Ramírez Carrillo, en Ruz (2002).
} 


\section{Comunidades tradicionales}

Dentro de este universo de 44 municipios, es fundamental resaltar dos de ellos: Valladolid y Chemax. Valladolid es la ciudad más importante del oriente y después de Mérida, la más poblada del estado. Precisamente por esto destaca que en su territorio se encuentren también como comisarías y pueblos dependientes, algunas de las comunidades más tradicionales, y quizá las únicas en donde todavía se conservan los antiguos sistemas de cargos como manifestación de la personalidad política de la comunidad maya. Es decir, que no sólo existen sistemas y procesos locales de toma de decisiones y de arreglos de la vida comunal a través de asambleas o de elecciones colectivas, como en muchas comunidades indígenas, sino que todavía hay una estructura de posiciones de poder que configura un liderazgo estructural impuesto sobre la comunidad y sobre el liderazgo natural. Difícilmente podemos plantear que esta estructura de cargos, tal como la conocemos hoy en día, corresponda a formas de organización indígena colonial, pero ciertamente es un arreglo de poder que se puede remontar hasta el siglo xIx como consecuencia de la Guerra de Castas.

En el municipio de Valladolid destaca Kanxoc como comunidad maya conservadora y autónoma, con un discurso y un pensamiento milenarista compartido por la población. En el municipio también hay que considerar a las comisarías de Xocén, Tixhualactún, Ticuch y Pixoy como sumamente tradicionales.

El segundo municipio en importancia en términos de conservadurismo cultural maya es el de Chemax. Éste es quizá más importante que los otros, que no tienen más de 2000 habitantes, pues es cabecera municipal, y su población llegó en 1995 a 18500 personas. Podemos considerar a Chemax como una capital maya del oriente, erigida frente a Valladolid, la capital mestiza. ${ }^{42}$ Además de una estrecha dependencia a la milpa y de un elevado monolingüismo, lo que podemos encontrar en estas comunidades es el uso de la vestimenta tradicional en toda la población y la práctica extendida y detallada de todos los rituales y ceremonias asociados al cultivo de la milpa.

Existen, además, dos sistemas de cargos, uno de carácter militar y otro de carácter religioso. Los cargos de carácter militar son conocidos como La guardia y se integran de manera jerárquica por comandantes, sargentos, cabos y soldados. En ellos participa o debe de hacerlo toda la población masculina del pueblo, efectuando una guardia armada y rotatoria con batallones de 25 hombres. Este sistema de cargos militares está integrado al poder formal, que representan el comisario municipal y el ejidal, elegidos a través de asamblea y consenso por las facciones con más poder de los pueblos. El segundo sistema es el religioso, que se encarga de ordenar y ejecutar los distintos rituales mayas en las comunidades. Su función se expresa en tres dimensiones: la organización

\footnotetext{
${ }^{42}$ Fay Brown (1993 y 1999).
} 
de las fiestas patronales, de los rituales correspondientes a la milpa y otras actividades productivas, y los rituales asociados a las distintas etapas de la vida familiar, desde el nacimiento hasta la muerte. Los h-menob que están a la cabeza de los cargos religiosos suelen ser vitalicios, no así los que desempeñan actividades rituales menores, quienes pueden ser hombres designados por ellos. Las mujeres están excluidas de los sistemas de cargos militares y religiosos. ${ }^{43}$

\section{Mayas urbanos}

De los 106 municipios de Yucatán, ocho no se consideran indígenas. Se trata de siete municipios de la costa y el de la ciudad de Mérida, de la que hasta ahora sólo hemos incluido a las 24 comisarías, donde más de $30 \%$ de la población habla maya. Pero esto resulta una falsa apreciación que es necesario destacar, pues si bien los otros municipios de la costa que quedan excluidos como mayas no tienen una población sustantiva, Mérida tenía en 1995 una población de más de cinco años que hablaba maya de casi 90000 personas (89 984), lo que de hecho la convierte en el centro más importante de maya hablantes no sólo del estado sino de toda la península de Yucatán. Para darnos una idea, en 1995 la ciudad con una mayor cantidad de población maya hablante era Valladolid, con 29853 personas, la tercera parte de los mayas que habitan en Mérida. Es más, para 1995 en Mérida aún había 624 personas que únicamente hablaban maya; más monolingües que en muchas comunidades medianas de la zona maicera. ${ }^{44}$

La globalización ha impactado de manera importante en la península de Yucatán al menos en tres sectores que se relacionan de manera directa con la población maya tanto en el orden económico como en el cultural. Primero el turismo; un fenómeno que genera no sólo nuevas actividades económicas, sino también nuevas formas de comportamiento, nuevos valores, y finalmente puede generar nuevas identidades culturales. El crecimiento del turismo en la península de Yucatán ha sido intenso. El desarrollo de Cancún, ciudad que creció de cero a 400000 habitantes en 30 años; entre 1970 y el 2000, acompañada de la inversión hotelera en los 200 kilómetros de la Riviera Maya y de Playa del Carmen y Tulum, que con más de tres millones de visitantes han llegado a aportar en algunos años hasta $30 \%$ del ingreso turístico total del país, ingresos que le han permitido a Quintana Roo mantener ritmos de crecimiento de su producto interno bruto superior a $8 \%$ anual desde 1990 , uno de los más altos de México. Este turismo ha representado un fuerte impacto económico y cultural sobre los mayas yucatecos.

Una incidencia que se ha experimentado no sólo en las comunidades mayas tradicionales de Quintana Roo, una treintena de pueblos agrupados entre Feli-

\footnotetext{
${ }^{43}$ Ramírez Carrillo, en Ruz (2002).

${ }^{44}$ Cfr. Güémez (2004).
} 
pe Carrillo Puerto, el viejo Chan Santa Cruz ${ }^{45}$ y Cancún mismo, sino en especial en más de 400 pueblos milperos y ganaderos del oriente, sur y noreste de Yucatán, e incluso en algunas ciudades pequeñas como Valladolid o Chemax, que en conjunto han aportado durante casi dos generaciones los mayores contingentes de fuerza de trabajo a la industria de la construcción y de la hotelería y los servicios de toda la Riviera.

Considerando la densidad demográfica de las áreas impactadas sugerimos que un contingente difícil de precisar pero que puede fluctuar entre $150000 \mathrm{y}$ 300000 mayas se ha visto involucrado en distintas etapas de su ciclo de vida, pero siempre durante varios años, en las actividades de la vida turística de la zona. Incluso en comunidades del oriente tan tradicionales como Chemax, Kanxoc, Xocén o Tixhualactún, es dificil encontrar una familia que no haya tenido o tenga un miembro trabajando de manera constante en Cancún. De 15 a $25 \%$ de los mayas yucatecos, probablemente la mitad de la población masculina adulta de los municipios del oriente, sur y noreste de Yucatán, se vincula a la migración temporal y está expuesta a la "experiencia Cancún y de la Riviera Maya" en algún período prolongado de su vida entre los 15 y los 35 años de edad.

El trabajo de los mayas en los servicios turísticos impacta a la comunidad como cualquier otra migración temporal, trastocando el orden de la economía, de las jerarquías tradicionales y la organización familiar, pero además transforma los valores mayas tradicionales en lo que respecta a las expectativas de vida, los ideales de consumo, las prácticas sexuales, el atuendo y los espacios domésticos y tipos de vivienda ideales. ${ }^{46}$ Estos cambios pueden verse reflejados en las comunidades mayas de la zona que viven la modernización que les permite la pobreza, no sólo en lo económico sino también en lo cultural, como valor y práctica vivida - y en lo ideológico — como aspiración nunca consumada pero que orienta de manera subjetiva las aspiraciones de vida.

La segunda actividad que es interesante discutir en cuanto a impactos de carácter cultural y económico entre los mayas y la globalización en Yucatán, es la presencia de plantas maquiladoras; el intento de abrir la frontera sur de la maquila mexicana. Aquí tenemos que ser muy objetivos en cuanto a su importancia, no sólo para los mayas sino para toda la población de Yucatán. En efecto, muy atentos a lo nuevo se han exagerado su desarrollo y sus efectos, y conviene analizarlos con un poco de detalle. ${ }^{47}$

El proyecto maquilador del sur de México se ha desarrollado en lo fundamental en el estado de Yucatán con una mínima presencia de plantas maquiladoras

\footnotetext{
${ }^{45}$ Véase el análisis sobre el impacto del turismo de Dufresne (1994) y Dachary (1997). Una década después de los estudios es aún más acelerado. Sobre el impacto de los programas de gobierno, cfr. Villagómez Valdés y Pinto (1997).

46 En referencia a estos aspectos véase en especial a Fay Brown (1999) y Dufresne (1994).

${ }^{47}$ Un análisis temprano de la maquila consta en Ramírez (1993).
} 
en Campeche y Quintana Roo. ${ }^{48}$ En Yucatán comienza como proyecto de Estado en 1984 y hasta la firma del TLC crece a un ritmo interesante, instalándose unas 50 plantas maquiladoras en una década, pero a partir de la devaluación y crisis de 1995 el ritmo se incrementó, y en noviembre del año 2000 crecen hasta llegar a 145 plantas y 38000 empleos. La recesión del mercado y la entrada de China al mercado de capitales las afecta, al igual que al resto de la industria maquiladora instalada en México. En julio del 2004 existían 130 maquiladoras con 32000 empleos, habiéndose perdido 15 fábricas y 6000 empleos en tres años y medio. El fenómeno es interesante por varias razones: es capaz de incorporar como obreros industriales a una mano de obra proveniente del sector comercio, servicios e incluso de la agricultura; emplea de manera mayoritaria mujeres, pues $75 \%$ de la fuerza de trabajo es femenina; y estudios recientes indican que puede generar nuevas identidades laborales de manera profunda y duradera entre las mujeres mayas que participan en la maquiladora, ${ }^{49}$ identidades que a su vez empoderan a las mujeres, es decir, modifican los papeles de género y los equilibrios de poder en el interior de la familia y las relaciones de pareja. Después de 20 años no se puede minimizar el impacto profundo de la maquila en las identidades laborales, y su capacidad de transformar a las y los mayas en obreras y obreros, con el consiguiente avance hacia otros campos de la vida cotidiana y la modificación de formas de vida tradicionales de la familia maya. ${ }^{50}$

Sin embargo, los cambios provocados por la maquila ni son tan amplios ni son tan profundos. No son tan amplios, primero, porque en el contexto del empleo y la dinámica laboral de los mayas, la maquila representa una actividad menor. Interesante como es, la importancia del empleo maquilador se ha exagerado. De las plantas consideradas como tales, la mayor parte son pequeñas textileras, y el peso de la inversión y el empleo recae en unas 60 plantas, de inversión mayoritaria o exclusivamente extranjera. El resto son pequeñas industrias de inversión mixta que suelen durar pocos años, o bien antiguas fábricas de ropa que sólo cambiaron de régimen para aprovechar los incentivos a la exportación. El sector manufacturero fluctúa entre 22 y $26 \%$ del empleo en Yucatán, sigue siendo menor que el comercio y los servicios; y dentro del sector manufacturero, otras actividades dan más empleo que la maquila. ${ }^{51}$

Por otra parte, pese a la política de desconcentración territorial de la industria maquiladora para tratar de instalarla en el campo yucateco y abrir oportunidades de empleo a una población mayoritariamente maya, el $72 \%$ del empleo y la inversión siguen ubicándose en el municipio de Mérida, por lo que el mayor impacto se ha dado entre mujeres pobres, urbanas, de origen maya y de

\footnotetext{
${ }^{45}$ Las razones de la concentración de la maquila en Yucatán pueden consultarse en Ramírez

${ }^{49}$ Véanse Castilla Ramos y B. Torres (1998).

${ }^{50}$ Castilla Ramos (2004).

${ }^{51}$ Cfr. Ramírez Carrillo (2004: 77-99).
} (2004). 
colonias periféricas de la ciudad y algunas de sus comisarías cercanas. Población maya que ya era la menos tradicional y más aculturada del estado. Sólo algunos poblados mayores como Motul, en la ex zona henequenera, o Maxcanú, se han visto impactados con el establecimiento de grandes maquiladoras, como la fábrica de pantalones de mezclilla Lee, de capital coreano, que con 5000 empleos ha transformado a Motul en un auténtico "Industrial Town", o ta'un en yucateco. ${ }^{52}$

La dinámica de las identidades y del cambio cultural son siempre caminos de ida y vuelta. Los mayores ingresos que permite la maquila reviven antiguos patrones culturales, como las fiestas patronales y los gremios, las fiestas de muertos y la cocina tradicional. La legitimación de las fábricas pasa por introducir al espacio laboral santos, relaciones de parentesco y formas de cortejo que se iban diluyendo. El trabajo femenino modifica los papeles de género pero detiene procesos de nuclearización, y vuelve a tejer la red de familias extensas en descomposición..$^{53}$ La maquila crea obreras y obreros pero retiene población, y en ese sentido fortalece la comunidad. Además, si concedemos que Yucatán tiene una población de 800000 mayas, y que de éstos unos 400000 hombres y mujeres constituyen la población económicamente activa de la etnia, la maquiladora no está empleando a más de $8 \%$ de esa PEA, y lo hace mayoritariamente con los mayas más transformados, los que viven en la ciudad de Mérida. ${ }^{54}$

Ahora bien, los impactos que atribuimos a la globalización no son en muchos sentidos cualitativamente distintos de los procesos de aculturación que se venían dando desde los años setenta. Sin embargo, podemos señalar algunos elementos que se acentúan con mayor fuerza durante los últimos años,

Los primeros corresponden a cambios en las identidades de género y en las identidades laborales entre los mayas, especialmente visible entre los mayas de Mérida, los de la ex zona henequenera y entre los del oriente. Estos cambios han sido provocados por una feminización del mercado de trabajo y la aparición de una incipiente cultura obrera provocada por las maquiladoras y el asalariamiento urbano en el sector turismo y de servicios. Esta transformación, dos caras de una misma moneda, puede ser considerada, por sus consecuencias, una verdadera revolución silenciosa de las formas tradicionales de organización familiar, de las relaciones de género y de los equilibrios tradicionales de poder, sustento de la desigualdad familiar y comunal que también han mantenido durante siglos las tradiciones culturales mayas.

En seguida debemos mencionar los cambios provocados por movimientos poblacionales y demográficos. Principalmente tres, que con distintas dinámicas

\footnotetext{
${ }^{52}$ Véase el estudio comparativo de las maquiladoras y su impacto en distintas áreas mayas de Yucatán en Simón Domínguez (2004).

${ }^{53}$ Consúltese Ramírez, 2004.

${ }^{54}$ Para una evaluación reciente del impacto general de la maquila, véase Mendoza Fernández (2004).
} 
impactan la tradicional organización cultural maya: La emigración hacia Estados Unidos, que se ha incrementado desde 1990, particularmente en los municipios del sur de Yucatán —las ciudades de Los Ángeles y Chicago poseen fuertes comunidades de migrantes mayas- - La migración hacia Mérida y sus cinco municipios conurbados, en particular de mayas provenientes del norte de Yucatán, de los municipios de la ex zona henequenera; y la migración estacional hacia el Caribe - Cancún, Playa del Carmen, Tulum y Cozumel-que, aunque se da en todo Yucatán, es más visible en los municipios mayas del oriente.

En resumen, la globalización ha impactado la península de Yucatán convirtiendo a Cancún y Mérida en ciudades cosmopolitas dominantes que median entre los procesos macro y microsociales. Por otra parte, la modernización cultural y económica provocada por la globalización en Yucatán se abre paso a través del desmantelamiento del monocultivo del henequén y de la monocultura que imperó por más de un siglo. En el campo yucateco, la globalización y la modernidad han ganado terreno en buena parte debido a la fuerte corriente migratoria hacia el vecino estado de Quintana Roo. Los ejes del cambio rural son la diversificación económica y la profundización de las relaciones de mercado por un lado, y los movimientos de población, migraciones internas y migraciones de retorno por el otro. La diversificación económica, en este contexto, significa crisis agrícola y empobrecimiento crónico no sólo del campesino sino de la sociedad rural en su conjunto. ${ }^{55}$

Las migraciones temporales en Yucatán explican una tradicionalidad que no acaba de extinguirse, y una modernidad que no termina de madurar, y si bien los desplazamientos definitivos campo-ciudad no han cesado, en diversas comunidades mayas han sido sustituidos por otro tipo de movilidad de la población, como las migraciones estacionales. ${ }^{56}$ La migración temporal es la más común en Yucatán, y los actores rurales se mueven entre el orden tradicional y el moderno, no sólo en el terreno económico sino también en el simbólico. Esto es un cambio profundo en la cultura y los individuos. Aun los que viven en el campo están más instalados en la modernidad que en la tradición.

Quisiera finalizar con la idea de la globalización como modernidad. Cuando analizamos el cambio social, como aquí se hace para Yucatán, comparando dos situaciones con respecto a una línea de tiempo o bien a un sujeto social ubicado en dos momentos distintos (la población maya), la idea de modernidad distingue la novedad del presente como corte o ruptura con el pasado. La moder-

\footnotetext{
${ }^{55}$ Una visión del empobrecimiento de la sociedad rural yucateca en su conjunto, interpretada más como pérdida de identidad indígena que como continuidad, la encontramos en Baños (2003).

${ }^{56}$ Para el impacto de las migraciones temporales en los mayas yucatecos, véanse ibid., pp. 117 174 y Gaultier (2001). El choque más profundo de la globalización en la cultura maya yucateca pasa por una transformación imaginaria del espacio cotidiano antes que por una transformación real del espacio, producto de la migración temporal de los jóvenes mayas que al retornar traen el cambio. Véase también Balam Pereira et al. (2002).
} 
nidad, entonces, desempeña un papel dual como categoría de periodización histórica: registra la contemporaneidad de una época en el momento de su clasificación, pero la registra en términos de una temporalidad cualitativamente nueva que siempre se trasciende a sí misma y tiene el efecto simultáneo de distanciar al presente de una manera continua de su pasado más reciente. Lo que quiero decir con esto, es que la modernidad en términos antropológicos y sociológicos constituye más un recorte analítico, una abstracción del observador, que una forma concreta, exacta, de la realidad. Que cuando decimos que los mayas yucatecos se encuentran instalados en la globalización nos referimos a fenómenos específicos pero diferenciados entre sí, como formas de comer y vestir, tipos de subordinación económica y en especial un imaginario de vida que conforma una nueva identidad, instalada en la modernidad, distinta a la anterior, que al parecer antes no lo estaba. Esta interpretación es muy valiosa y válida, siempre y cuando recordemos que la modernidad no tiene un referente fijo, objetivo, sino que sólo tiene un sujeto que la colma. Decir que un maya yucateco es moderno o pertenece a la modernidad y no a la tradición, es decir nada más que hay un acto de autodefinición histórica. Es decir, que se identifica y proyecta con un presente significativo; su presente. El contenido de este presente es siempre relativo a su ubicación histórica y a sus proyectos imaginados. Es por ello que su modernidad no sólo es resultado de la pobreza y la desigualdad, sino que la reproduce y perpetúa, aunque le haga cambiar sus formas de vida y sus expectativas de consumo, y le haga construir otro imaginario.

Nunca como en esta modernidad provocada y arrastrada por la pobreza, en esta modernidad que acompaña y expresa la globalización, y que reproduce la miseria con nuevos contenidos e imágenes, queda claro el carácter original del concepto teórico de imaginario, que es el de la alienación, alienación que se observa en todos los órdenes de vida.

El concepto sociológico del imaginario de lo moderno se refiere no sólo al desarrollo de una capacidad para formar nuevas imágenes de la realidad, sino también al efecto alienante de la identificación con ellas, a la consecuencia de pensar que estas imágenes son la realidad. Y desde la pobreza de un campesino maya yucateco, la inserción en la globalización y modernidad, la mayor parte de las veces, sólo puede ser ésta, la imaginada. En la medida en que esta inserción en la modernidad global es más imaginada que real, habrá que ver qué tan duradera es, pues esta pobreza, por desgracia, es uno de los bastiones que mantiene viva la tradición y permite la reproducción de la sociedad indígena de los mayas yucatecos.

\section{BIBLIOGRAFÍA}

Askinasy, Siegfried

1936 El problema agrario de Yucatán. México: Botas. 
Azais, Christian

2003 "Los territorios de la maquila en el estado de Yucatán", en Territorios, actores y poder, pp. 377-419, J. Preciado, H. Riviere, L. A. Ramírez y M. PepinLehalleur (coords.). México: UAG-UADY.

Balam Pereira, Gilberto

1991 Cosmogonía y uso actual de las plantas medicinales de Yucatán. Mérida: UADY.

Ernesto Ochoa Estrada y Genny Sonda

2002 "La migración de mayas yucatecos al Caribe", Revista de la Universidad Autónoma de Yucatán, vol. 16-17 (219-220): 29-33. México: UADY.

2004 "La desnutrición en Yucatán desde una perspectiva histórico-social", Revista de la Universidad Autónoma de Yucatán, vol. 19 (228): 3-7. México: UADY

Baños, Othón

1996a "Tendencias recientes del desarrollo regional: el caso de Yucatán", Comercio Exterior, 46 (8): 636-643. México: BANCOMEXT.

1996b Neoliberalismo, reorganización y subsistencia rural. Mérida, Yucatán: Universidad Autónoma de Yucatán.

2003 Modernidad, imaginario e identidad rurales: el caso de Yucatán. México: El Colegio de México.

Barman, Zygmunt

1999 La globalización. Consecuencias humanas. México: FCE.

Barrera Vázquez, Alfredo

1980 "Introducción", Diccionario maya-español Cordemex, pp. 15-37. Mérida, Yucatán: Cordemex

1980a "La lengua maya de Yucatán", en Enciclopedia Yucatanense, t. VI: 205-292, 2a ed. ampliada a XII vols. Mérida: Gobierno del Estado de Yucatán.

1980b "El dioma español en Yucatán", en Encilopedia Yucatanense, t. VI: 341-375, 2a ed. ampliada a XII vols. Mérida: Gobierno del Estado de Yucatán.

Bartolomé, Miguel Alberto y Alicia Barabas

1977 La resistencia maya: relaciones interétnicas en el oriente de la península de Yucatán. México: INAH.

Bartra, Armando

1978 Apuntes sobre la cuestión campesina. Centro de Investigaciones Regionales Dr. Hideyo Noguchi, Universidad Autónoma de Yucatán. Mérida: DEES (Cuaderno, 81).

Benítez, Fernando

1962 Ki, el drama de un pueblo y una planta. México: FCE. 
Bonfil Batalla, Guillermo

1962 Diagnóstico sobre el hambre en Sudzal, Yucatán: un ensayo de antropología aplicada. México: Investigaciones Históricas, INAH.

Borja, Jordi y Manuel Castells

2002 Local y global. México: Taurus.

Bracamonte y Sosa, Pedro

2002 "Quintana Roo", en Los mayas peninsulares. Un perfil socioeconómico, pp. 107. 131, M. H. Ruz (coord.). México: UNAM, IIFL, Centro de Estudios Mayas (Serie Cuadernos, 28).

Castilla Ramos, Beatriz

2004 "Celles qui ont passé le pont: travail en usine et communauté", en Les formes de reconnaissance de l'autre en question, pp. 137-144, Ben Naoum Ahmed et al. (eds.). Perpignan, Francia: Presses Universitaires de Perpignan (Collection Études).

- - Beatriz Torres

1998 "Algunos aspectos de la reestructuración productiva en los establecimientos manufactureros yucatecos", El Cotidiano, 89: 18-30. México: UAM Azcapotzalco.

Dachary, César

1997 "El turismo sostenible en el Caribe", Revista Mexicana del Caribe, 4: 164-183: Chetumal, México: Universidad de Quintana Roo, CONACYT, CIESAS, Instituto Mora y Asociación Mexicana de Estudios del Caribe.

Dufresne, Lucie

1994 "Evolución de la región maya e impactos del turismo en la península de Yucatán, 1970-1993", Revista de la Universidad Autónoma de Yucatán, 190: 58-67. Mérida: Universidad Autónoma de Yucatán.

1999 Les mayas et Cancún. Montreal: Presses de la Université de Montreal (Col. Americanistes).

Fay Brown, Denisse

1993 "Yucatec maya settlings. Settlement and spatiality". Tesis doctoral en Arqueología. Riverside: Universidad de California.

1999 "Espacios mayas de familia y comunidad: una relación de interdependencia", Mexican Studies-Estudios Mexicanos, 15 (2): 323-342. México: Centro de Investigación y Docencia Económicas.

Fort, Odile

1979 La colonización ejidal en Quintana Roo, México. México: Instituto Nacional Indigenista. 
Gaultier, Sebastián

2001 "La migration rurale-rurale dans le sud-est mexicain et ses interrelations avec les nouveaux systems de production localises: le cas de la peninsule du Yucatán". Tesis doctoral en Geografia. París: Paris III, Sorbonne Nouvelle.

Gravel, Nathalie

2003 "La nueva regionalización en Yucatán de cara al fenómeno de la globalización", en Territorios, actores y poder, pp. 355-376, J. Preciado, H. Riviere, L. A. Ramírez y M. Pepin-Lehalleur (coords.). México: UAG-UADY.

Giiémez Pineda, Miguel A.

2004 "La lengua maya en el contexto sociolinguíístico de la península de Yucatán", en The Consortium in Latin American Studies. Carolina del Norte: The University of North Carolina at Chapel Hill and Duke University (Working paper, no. 37).

s.f. "Representaciones y prácticas sociales ante el proceso de embarazo, parto puerperio y las complicaciones asociadas". Tesis doctoral en Antropología social. México: UNAM, Instituto de Investigaciones Antropológicas y Facultad de Filosofía y Letras (en proceso).

Guzmán Medina, María Guadalupe Violeta

2002 "Los mayas: identidad, cultura y poder". Tesis doctoral en Antropología social. México: UNAM, Instituto de Investigaciones Antropológicas y Facultad de Filosofía y Letras.

Hansen, Azael y Juan Ramón Bastarrachea

1984 Mérida. Su transformación de capital colonial a naciente metrópoli en 1935. México: INAH.

Ianni, Octavio

1999 La era del globalismo. México: Siglo XXI

INEGI

2000 XIl Censo general de población y vivienda. México: INEGI.

Kazancigil, Ali (ed.)

1988a "The local-global nexus", International Social Science Journal, 117: 321-340. Oxford: Blackwell/UNESCO.

1988b "Modernity and identity: a symposium", International Social Science Journal, 118: 459-467. Oxford: Blackwell/UNESCO.

Lerman, Aida (comp.)

1999 Globalización-regionalización. México: UAM Xochimilco.

López, Francisco y Daniel Filmus (coords.)

2000 América Latina 2020. Guatemala: FLACSO y UNESCO. 
Macossay, Mauricio

1988 La agroindustria henequenera yucateca. Una visión global. Mérida: Universidad Autónoma de Chapingo, Centro Regional Península de Yucatán.

2004 "Tradición y cambio rural, la identidad campesina maya en los horticultores de Dzidzantún, Yucatán", Revista de la Universidad Autónoma de Yucatán, vol. 19 (229): 28-50. México: Universidad Autónoma de Yucatán.

Morley, Sylvanus

1965 La civilización maya, $5^{\text {a }}$ ed. México: FCE.

Mossbrucker, Harold

1992 "Etnia, cultura y el impacto de la migración entre los mayas de Yucatán", América Indígena, vol. LII (4): 187-214, octubre-noviembre. México: Instituto Indigenista Interamericano.

Mendoza Fernández, María Teresa

2004 "La industria maquiladora de la confección en Yucatán", en La industria de la confección en México y China ante la globalización, pp. 193-211, I. Rueda Peiro, N. Simón Domínguez y M. L. González Marín (coords.). México: Miguel Ángel Porrúa.

Ohmae, Kenichi

1986 Triad Power. Nueva York: The Free Press.

Pacheco Cruz, Santiago

1962 Antropologia cultural maya, t. I. Mérida, Yucatán: Ediciones del autor.

1964 Antropología cultural maya, t. II. Mérida, Yucatán: Ediciones del autor.

Paré, Luisa

1982 El proletariado agrícola en México. México: Siglo XXI.

Pérez Toro, Augusto

1977 "La agricultura milpera de los mayas de Yucatán", Enciclopedia Yucatanense, t. VI: 173-204, C. Echánove Trujillo (ed.). Mérida: Gobierno del Estado de Yucatán.

Pfeiler, Barbara

1997 "El maya: una cuestión de persistencia o pérdida cultural", en Persistencia cultural entre los mayas frente al cambio y la modernidad, pp. 55-77, R. Arzápalo Marín y R. Gubler (comps.). Mérida: Universidad Autónoma de Yucatán.

Porter, Michael (ed.)

1986 Competition in Global Industries. Boston: Harvard Business School Press.

Preciado J., H. Riviere, L. A. Ramírez y M. Pepin Lehalleur (coords.)

2003 Territorios, actores y poder. México: UAG-UADY. 
Ramírez Carrillo, Luis Alfonso

1986 Chilchota, un pueblo al pie de la sierra. México: El Colegio de Michoacán.

1993 Sociedad y población urbana en Yucatán. México: El Colegio de México.

2000 Historia regional de Yucatán. México: SEP-Limusa.

2002a "Yucatán", en Los mayas peninsulares. Un perfil socioeconómico, pp. 47-78, M. H. Ruz (coord.). México: UNAM, IIFL, Centro de Estudios Mayas (Serie Cuadernos, 28).

2002b Mujeres de Yucatán y Mérida. Mérida: Ayuntamiento de Mérida.

2003 "La ronda de las elites: región y poder en Yucatán", en Territorios, actores y poder; pp. 191-219, J. Preciado, H. Riviere, L. A. Ramírez y M. Pepin-Lehalleur (coords.). México: UAG-UADY.

2004 "Un nouvel ordre culturel pour d'anciennes identités: la femme, la communauté et les indigenes au Mexique", Les formes de reconnaissance de l'autre en question, pp. 433-450, Ben Naoum Ahmed et al. (eds.). Perpignan, Francia: Presses Universitaires de Perpignan (Collection Études).

En prensa Las redes del poder. Corrupción, maquiladoras y desarrollo regional: el caso de Yucatán. México: Miguel Ángel Porrúa.

Re Cruz, Alicia

1994 "Lo sagrado y lo profano de la identidad maya entre los migrantes de Yucatán", Nueva Antropología, vol. XIV (46): 39-48. México: CONACULTA, INAH.

1996 The Two Milpas of Chan Kom. Scenario of a Maya Life. Albany, Nueva York: State University of New York.

Redfield, Robert

1941 The Folk Culture of Yucatán. Chicago: University of Chicago Press.

y Alfonso Villa Rojas

1934 Chan Kom: A Maya Village. Washington: Carnegie Institution of Washington (Publicacion 448).

Ruz, Mario Humberto

2002 "Los mayas peninsulares", en Los mayas peninsulares. Un perfil socioeconómico, pp. 7-45, M. H. Ruz (coord.). México: UNAM, IIFL, Centro de Estudios Mayas (Serie Cuadernos, 28).

Sierra O'Reilly, Justo

1951 "Los indios de Yucatán", en El Registro Yucateco (1): 165-178. Yucatán: UADY, Facultad de Ciencias Antropológicas. 
Sierra O'Reilly, Justo

1954 Los indios de Yucatán. Consideraciones históricas sobre la influencia del elemento indígena en la organización social del país. Mérida: C. R. Menéndez, 2 ts.

Simón Domínguez, Nadima

2004 "Estudio de caso de maquiladoras de la industria de la confección en Yucatán", en La industria de la confección en México y China ante la globalización, pp. 213-252, I. Rueda Peiro, N. Simón Domínguez y M. L. González Marín (coords.). México: Miguel Ángel Porrúa.

Solís Robleda, Gabriela

2002 "Campeche", en Los mayas peninsulares. Un perfil socioeconómico, pp. 79-104, M. H. Ruz (coord.). México: UNAM, IIFL, Centro de Estudios Mayas (Serie Cuadernos, 28).

Souza Novelo, Narciso

1948 El maíz. La milpa. Mérida, Yucatán: Instituto Tecnológico Agrícola Henequenero.

Steggerda, Morris

1941 Maya Indians of Yucatan. Washington: Carnegie Institution of Washington (Publicación 531).

Stephens, J. L.

1841 Incidents of Travel in Central America, Chiapas and Yucatan. Nueva YorK: Harper, 2 vols.

1843 Incidents of Travel in Yucatan. Nueva York: Harper, 2 vols.

Sullivan, Paul

1991 Conversaciones inconclusas. Mayas y extranjeros entre dos guerras. Barcelona: Gedisa.

Thompson, J. E.

1930 "Ethnology of the maya of southern and central British Honduras". Chicago: Field Museum of Natural History (Anthropological Series, vol. 17, no. 2).

1954 The Rise and Fall of Maya Civilization. Oklahoma: University of Oklahoma Press, Norman.

Thompson, Richard A.

1974 Aires de progreso. Cambio social en un pueblo maya de Yucatán. México: INI.

Trujillo, Narcisa

1977 "El maya de las haciendas henequeneras de Yucatán", en Enciclopedia Yucatanense, (VI): 133-171, C. Echánove Trujillo (ed.). Mérida: Gobierno del Estado de Yucatán. 
Villa Rojas, Alfonso

1978 Los elegidos de Dios. México: INI.

Villagómez Valdés, Gina y Wilbert Pinto

1977 Mujer maya y desarrollo rural en Yucatán. Mérida, Yucatán: Universidad Autónoma de Yucatán.

Villanueva, Eric

1983 Desarrollo capitalista y sujeción campesina en la zona citrícola de Yucatán. México: UNAM.

- (coord.)

1990 El henequén en Yucatán. Industria, mercado y campesinos. Mérida, Yucatán: Maldonado Editores.

Warman, Arturo

1985 Estrategias de sobrevivencia de los campesinos mayas. México: UNAM, Instituto de Investigaciones Sociales (Cuadernos de Investigación Social, 13). 